\title{
Obstrüktif Uyku Apne Sendromlu Bir Hastada Polisomnografi Tetkiki Esnasında Solunum Arrestine Bağlı Exitus
}

\section{Exitus Secondary to Respiratory Arest in a Patient with Obstructive Sleep Apnea During Polysomnographic Investigation}

\author{
Gülçin Benbir, Mecbure Nalbantoğlu, Derya Karadeniz \\ Istanbul Üniversitesi Cerrahpaşa Tıp Fakültesi, Nöroloji Anabilim Dalı, Uyku ve Bozuklukları Bölümü, Istanbul, Türkiye
}

\section{Özet}

Obstrüktif Uyku Apne sendromu (OUAS) komplikasyonları arasında hayati önem taşıyan hipertansiyon, inme, iskemik kalp hastalığı ve kardiyak ritim bozukluğu gibi hastalıklar yer almaktadır. Kırk yaşında kadın hasta, şeker hastalığı, hipertansiyon, hipofiz mikroadenomu ve Cushing sendromu tanıları ile Endokrinoloji servisinde yatmakta iken, gece uykusunda nefes durmalarının gözlenmesi üzerine uyku bozuklukları birimimize yönlendirildi. Hastanın son 10 yıldır horlama, terleme, sabah yorgun uyanma ve gündüz aşırı uykululuk şikayetleri olduğu öğrenildi. Polisomnografi tetkikinde solunum kayıtlarında NREM uyku evresinde sürekli, saatte 60 sıklığında tekrarlayan obstrüktif tipte hipopneler kaydedildi. Hastanın REM uyku evresine girmesi ile birlikte 100 saniye süreli santral apne ve bunu takiben bradikardi ve kardiyak arrest gelişmiş, hasta tüm müdahalelere karşın kurtarılamamıştır. Burada, hayati riskleri olan ancak etkin tedavisi (invaziv olmayan mekanik ventilasyon) ile tüm komplikasyonları ortadan kaldırılabilen önemli bir nörolojik hastalık olan obstrüktif uyku apne sendromuna tüm branştaki hekimlerin dikkatinin çekilmesi hedeflemiştir. Özellikle hipertansiyon, obezite ve kalp hastalıkları gibi eşlik eden komorbiditelerin varlığında dikkatlice sorgulanmalı ve ivedilikle tedavi edilmelidir. Sunulan olguda olduğu gibi tanı ve tedavideki gecikmeler, ölümcül sonuçlar doğuracaktır. (JTSM 2014;1:33-5)

Anahtar Kelimeler: Obstrüktif uyku apne sendromu, santral apne, kardiyak ritim bozukluğu

\section{Summary}

Obstructive sleep apnea syndrome (OSAS) has severe, life-threatening complications such as hypertension, stoke, ischemic heart disease or rhythm problems. A 40-year old woman was referred to our sleep laboratory due to witnessed apnea during her hospitalization in endocrinology yard because of hypertension, hipophyseal microadenoma and Cushing syndrome. Her past medical history revealed that she had snoring, sweating at night, tiredness in morning and excessive daytime sleepiness for the last 10 years. In polysomnography investigation, we observed continuous obstructive hypopneas during NREM sleep stage with an index of 60 (times per an hour). As she started to have REM sleep stage, she had a central apnea lasting for 100 seconds, followed by bradicardia and cardiac arrest; the patient was lost in spite of urgent intervention. Here we aimed to attract attention of physicians from all disciplines to OSAS, which is a neurological life-threatening condition but all complications could be removed by non-invasive mechanical ventilation therapy. Especially in the presence of hypertension, obesity and cardiac disorders, OSAS should be questioned in detailed and be treated immediately. Otherwise, delay in diagnosis and treatment would result in lethal consequences, as in the patient reported here. (JTSM 2014;1:33-5)

Key Words: Obstructive sleep apnea syndrome, cantral apnea, cardiac rhythm abnormality

\section{Giriş}

Obstrüktif uyku apne sendromu (OUAS) tanısı, başka bir nedene bağlı olmayan gündüz aşırı uykululuk ile birlikte uykuda boğulma-tıkanma hissi, gece içi sık uyanmalar, dinlendirici olmayan uyku, gece terlemesi, noktüri, gündüz yorgunluk ve konsantrasyon bozukluğu bulgularından herhangi ikisinin varlığı ile birlikte polisomnografi (PSG) tetkikinde belirtilen tanı kriterlerinin karşılanması durumunda konulmaktadır. OUAS, tüm toplumlarda oldukça sık olarak gözlenir; erkeklerde en az $\% 4$, kadınlarda en az $\% 2$ olup yaşla artış gösterir ve erkeklerde
$\% 28^{\prime} \mathrm{e}$, kadınlarda ise özellikle menapoz döneminin başlamasıyla $\% 19^{\prime}$ a kadar yükselebilmektedir $(1,2)$.

Obstrüktif uyku apne sendromu, vasküler endotel fonksiyon bozukluğu, oksidatif stres artışı ve koagülasyon bozukluğuna yol açmakta olup, hipertansiyon, iskemik kalp hastalı̆̆ı şeker hastalığı, obezite ve serebrovasküler hastalıklar için bilinen diğer risk faktörlerinden bağımsız bir risk faktörüdür $(3,4)$. Burada, OUAS ön tanısı ile PSG tetkiki esnasında solunum ve kardiyak arresti gelişen ve tüm müdahalelere karşın geri döndürülemeyen bir hasta sunulmaktadır.

Yazışma Adresi/ Address for Correspondence: Dr. Gülçin Benbir, İstanbul Üniversitesi Cerrahpaşa Tıp Fakültesi, Nöroloji Anabilim Dalı, Uyku ve Bozuklukları Bölümü, İstanbul, Türkiye Tel.: +90 2126329696 E-mail: drgulcinbenbir@yahoo.com Geliş Tarihi/Received: 08.12.2013 Kabul Tarihi/Accepted: 02.03.2014 


\section{Olgu}

Kırk yaşında kadın hasta, diabetes mellitus, hipertansiyon (HT), hipofiz mikroadenomu ve Cushing sendromu tanıları ile Endokrinoloji servisinde yatmakta iken, gece uykusunda nefes durmalarının gözlenmesi üzerine uyku bozuklukları birimimize yönlendirilmiştir.

Hastanın son 10 yıldır horlama, terleme, sabah yorgun uyanma ve gündüz aşırı uykululuk şikayetleri olduğu öğrenilmiştir. Son iki yılda $80 \mathrm{~kg}$ alan hastanın şikayetlerinin bu dönemde belirginleştiği belirtilmiştir. Vücut kitle indeksi $72,8 \mathrm{~kg} / \mathrm{m}^{2}$ olarak hesaplanmıştır. OUAS ve uykuda hipoventilasyon-hipoksemik sendrom düşünülen hastada polisomnografi tetkiki planlanmış ve başvurusunu takiben dört gün sonra tetkike alınmıştır.

PSG tetkik gecesinde, odanın ışıkları 23:30'da kapatılmış, hasta bir dakika sonra uykuya dalmıştır. Solunum kayıtlarında sürekli sesli solunum ile birlikte, NREM uyku evresinde sürekli, saatte 60 sıklığında tekrarlayan obstrüktif tipte hipopneler kaydedilmiştir. Uyanıklık ortalama oksijen satürasyonu \%95 olup, minimum oksijen satürasyonu NREM uykusu esnasında \%83'e dek düşmüştür. Tetkik süresince hastanın uykuda sırtüstü pozisyona geçemediği dikkati çekmiştir. Anormal solunum olaylarına eşlik eden sık ventriküler ekstrasistoller ve braditaşiaritmiler izlenmiştir (Şekil 1).

Hasta uykuya daldıktan 102,5 dakika sonra REM uyku evresine girmiştir. Takiben, 100 saniye süreli santral apne izlenmiş, oksijen satürasyonu \%94'den hızla \%0'a düşmüştür (Şekil 2). Bunu takiben, EKG'de bradikardi ve elektroensefalografide yaygın yavaşlama gelişmiştir (Şekil 3). Tüm müdahalelere rağmen yanıt alınamayan hastada kardiyak arrest gelişmiş ve elektrokortikal aktivitenin tamamen kaybolduğu izlenmiştir.

\section{Tartışma}

Obstrüktif uyku apne sendromu ile ilişkili olarak görülen en sık kardiyak ritim bozuklukları atriyal fibrilasyon ve ventriküler ektopiler olabilmekle birlikte, sıklıkla apne-hipopneye karşı refleks olarak ortaya çıkan bradi-taşiaritmiler göze çarpmakta ve OUAS'ta bulunan artmış kardiyovasküler riskten sorumlu tutulmaktadırlar (5). Alonso-Fernandez ve arkadaşları minimum arteriyal oksijen satürasyon değerleri ile noktürnal sinüs bradikardisi ve ST depresyonunun eşlik ettiği supraventriküler

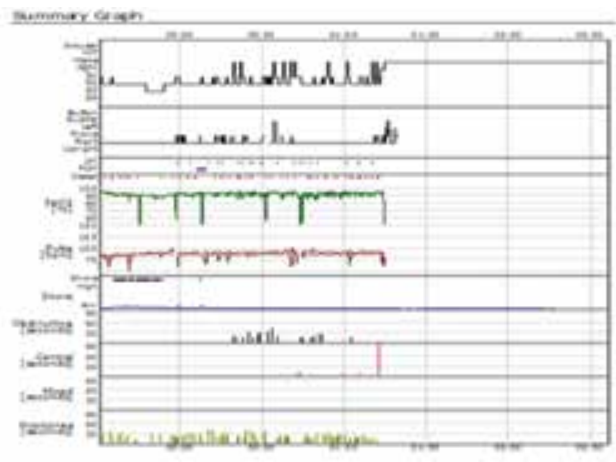

Şekil 1. Polisomnografi tetkik gecesine dair hipnogram.

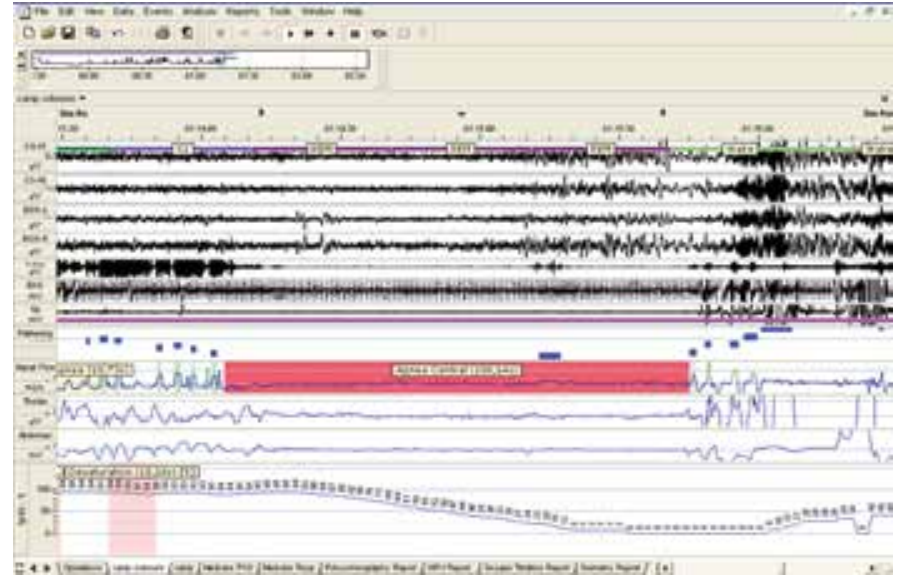

Şekil 2. REM uyku evresinde 100 saniye süreli santral apne ve oksijen satürasyonunda ani düşme.

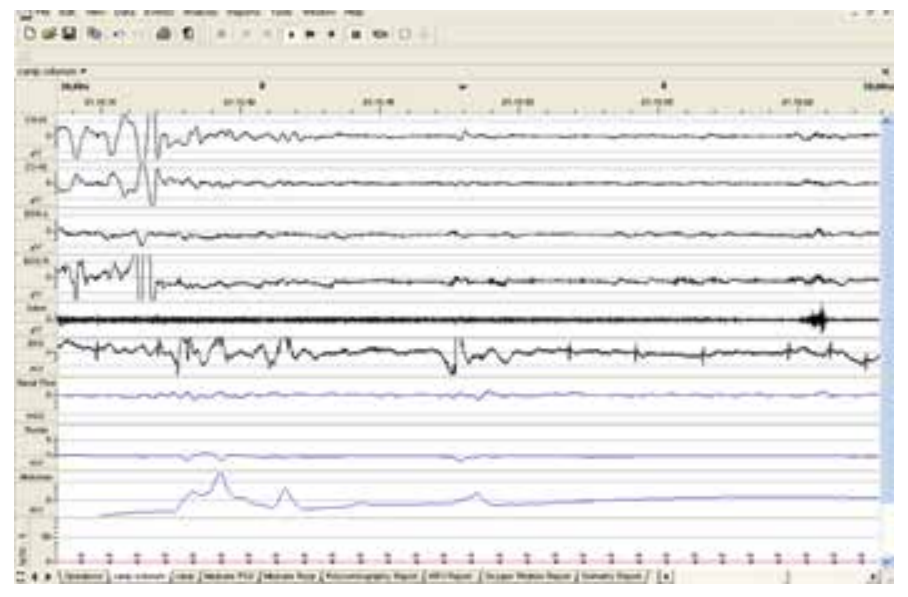

Şekil 3. Santral apne ve hipoksiyi takiben gelişen EKG'de bradikardi ve elektroensefalografide yaygın yavaşlama.

taşikardi arasında anlamlı bir ilişki olduğunu göstermişlerdir (6). Obstrüktif uyku apne sendromunda, apneler esnasında oluşan hipokseminin yanı sıra, adrenerjik aktivasyon, kan basıncı artışı ve artmış negatif intratorasik basınç sonucu oluşan kardiyak basının aritmilerin oluşması için yeterli olduğu kabul edilmektedir. Uyku ve kalp sağlığı çalışmasında da, apne ve hipopne indeksi 30 ve üzeri olan hastaların, inme için önemli bir risk faktörü olan atriyal fibrilasyon geliştirme riskleri 4 kat daha fazla bulunmuştur (7). Pataka ve ark. (8) yakın zamanda yayınladıkları bir bildiride, OUAS tanısı olan bir hastada gece içinde çok sayıda sinüs arresti yaşadığını ve bu durumun OUAS hastalarında gece görülen ani ölüm vakalarından sorumlu olabileceğini öne sürmektedirler. Bildiğimiz kadarıla, sunduğumuz vakada olduğu gibi santral apne ve buna sekonder gelişen sinüs arrestine bağlı exitus literatürde ilk kez bildirilmiştir.

OUAS, hayati riskleri olan ancak etkin tedavisi (invaziv olmayan mekanik ventilasyon) ile tüm komplikasyonları ortadan kaldırılabilen önemli bir nörolojik hastalıktır. Özellikle HT, obezite ve kalp hastalıkları gibi eşlik eden komorbiditelerin 
varlığında dikkatlice sorgulanmalı ve ivedilikle tedavi edilmelidir. Sunulan olguda olduğu gibi tanı ve tedavideki gecikmeler, ölümcül sonuçlar doğuracaktır.

\section{Kaynaklar}

1. Wierzbicka A, Rola R, Wichniak P, Richter P, Ryglewicz D, Jernajczyk $W$. The incidence of sleep apnea in patients with stroke or transient ischemic attack. J Physiol Pharmacol 2006;57 Suppl 4:385-90.

2. Young T, Palta M, Dempsey J, Skatrud J, Weber S, Badr S. The occurrence of sleep-disordered breathing among middle-aged adults. N Engl J Med 1993;328:1230-5.

3. Benbir G, Karadeniz D. Uyku ile ilişkili solunum bozuklukları: Obstrüktif uyku apne sendromu. Türkiye Klinikleri 2010;3:27-40.
4. Benbir G, Karadeniz D. Uykuda solunum bozuklukları nelerdir? Ne zaman, nasıl tedavi edilmelidir? Aktual Medicine 2013;21:10-7.

5. Wieber SJ. The Cardiac Consequences of the Obstructive Sleep Apnea-Hypopnea Syndrome. Mt Sinai J Med 2005;72:10-2.

6. Alonso-Fernandez A, Garcia-Rio F, Racionero MA, Pino JM, Ortuno F, Martinez I, et al. Cardiac rhythm disturbances and ST-segment depression episodes in patients with obstructive sleep-apneahypopnea syndrome and its mechanisms. Chest 2005;127:15-22.

7. Mehra R, Benjamin EJ, Shahar E, Gottlieb DJ, Nawabit R, Kirchner HL, et al; Sleep Heart Health Study. Association of nocturnal arrhythmias with sleep-disordered breathing. Am J Respir Crit Care Med 2006;173:910-6.

8. Pataka A, Daskalopoulou E, Papstefanou S, Baltatzi C, Aggelopulos P, Vlachogianni E. Mutiple heart pause during sleep in a patient with obstructive sleep apnea syndrome. Sleep Breath 2013;17:19-23. 